\title{
STUDENT FEATURE
}

\section{Improving the Freedom of Information Act Through the Office of Information Policy}

\section{Chelsea Webb}

Government transparency is a modern expectation of the United States of America's government operations. Information transparency can be found from presidential records to congressional hearings and can be found in places such as the Congressional Record, GPO databases and programs, and many other databases that house or link to government information. The Freedom of Information Act does well to ensure that citizens are able to stay informed and have the ability to request access to some federal agency information. In addition to this, the DOJ has the Office of Information Policy (OIP) that has set focus on continually improving the FOIA by launching an Open Government Initiative in 2010 and releasing three additional revisions by 2016. All plans continue to increasingly evolve the OIP, while dissecting the efficacy of the Open Government Initiatives across agencies that are required to disseminate information to the public. Exploration of dissemination of information relating to the OIP and the prevalence of access issues are discussed.

T he United States has seen periods of intense government secrecy that many feared was a huge threat to democracy and a precursor to a dictatorship. It increased especially during the Cold War which had heightened tensions from fears of communism inside the federal government. One of the biggest champions for government transparency, a Democrat in Congress by the name of John Moss, made it a point to gather his fellow politicians to pass the Freedom of Information Act that was signed by Lyndon B. Johnson in $1966 .{ }^{1}$ Since being passed the act has continued to get support through new amendments.

To understand the need for the Office of Information Policy it is important to understand what they are being tasked with overseeing. That is the Freedom of Information Act (FOIA) which was created in 1967 to explicitly give the public access (regardless of US citizenship) to request a variety of records from any of the federal agencies. ${ }^{2}$ Requests are placed with the relevant agency's FOIA office and are processed in the order they are received. Depending on how complex the request is and whether there is a current backlog, this may affect how quickly each can be processed. While the agency is required to respond to requests for records, they have the ability to exempt themselves from releasing specific information and can even partially release or redact documents. There are currently nine different exemptions from release in the FOIA: information pertaining to classified national security, internal personnel rules and practices of a specific agency, federally prohibited by law, trade or commercial secrets, privileged communications of agencies, individual personal privacy, law enforcement, financial institution supervision, and well geography. ${ }^{3}$

\section{Creation/Role of OIP}

Following the passing of the FOIA there remained a gap that needed to be filled for the legislation to be effective. It was not until December 8, 1969 that the Freedom of Information Committee was established to assist and advise agencies on the new act. ${ }^{4}$ Once the FOIA started receiving more traction the committee found itself transformed and shifted a few more times before settling as an independent section of the Department of Justice (DOJ) on May 14, 1993.' The current mission of the OAP is to "provide legal and policy advice to all agencies on administration of the FOIA."

All agencies are required to annually report their POIA activities to the Attorney General and OIP spearheads the policy for reporting and evaluating an agency's progress in FOIA compliance. The office, which reports to the DOJ's Office of the Associate Attorney General, has responsibility for the department's own litigation and compliance reports and handles judgments for FOIA administrative appeals. Senior leadership 
offices like the Attorney General also task the OIP with handling FOIA requests for them. While they take a lot of action for the DOJ, they must continue to make it easy for the public to get FOIA information that has been released and that is done by updating the FOIA.gov website. Finally, the office provides agencies with legal or policy advice alongside training programs to improve FOIA compliance and implementation. It is evident from the requirements of duty for the Office of Information Policy that they handle a large amount of government transparency oversight together with the Department of Justice's FOIA responsibilities. Even though they create guidelines and instruct on how to be FOIA compliant, they are still subject to new Attorney General guidelines and Presidential Memorandums that may influence their operations.

\section{Open Government Initiatives}

The Freedom of Information Act has seen multiple modifications over the years that have contributed to the strengthening of the act and a lot of substantial changes can be seen in just the last decade. One of former president's Obama's earlier memorandums clearly state directions towards the heads of all executive departments and agencies informing them and the public his intentions to have a new and "unprecedented level of openness in Government." 7 The biggest takeaways from that memorandum were that the government should explicitly be three things: transparent, participatory, and collaborative. The Chief Technology Officer, Director of the Office of Management and Budget (OMB), and Administrator of General Services were expected to get together with the necessary executive departments and agencies in order to develop an Open Government Directive within 120 days from the issuance of the memorandum. The Open Government Directive (M-10-06) detailed four goals to increase government transparency. The goals identified were making sure government information was published online, quality of government information will be increased and abide by OMB standards, breed a culture of open government through an open government plan in each agency, and invest in policy framework that allows for advancing technology that can help with open government. ${ }^{8}$

In November 2011, it was followed by another presidential memorandum titled Managing Government Records that addresses the heads of executive departments and agencies, but this time for the topic of reforming records management and policies. ${ }^{9}$ This memorandum attempts to reform records management policies and practices for the rapid increase of technological advances that directly affect agency operations. It also attempts to hold agencies accountable through their heads and requires the Director of OMB and Archivist of the United
States to create a records management directive to focus on a government wide records framework that will increase accountability and public access to government records. Former President Obama followed up with an executive order in 2013 that directly addresses openness of the government and creation of an Open Data Policy to ensure that government information remains accessible and exponentially increases government transparency. ${ }^{10}$ Motivation behind increasing government transparency through new memorandums can be attributed to classifying government data as an asset that has the potential to propel job growth and contribute to social advancements.

Prompted by President Obama's leadership and the Open Government Directive, the Department of Justice released a comprehensive Open Government Plan to address the new directive. The US Department of State also published their own plan detailing their new, expanded, and ongoing initiatives that include open data, records management, and FOIA requests. The Department of Justice's own version of their Open Government Plan from its inception on April 2, 2010, has been updated four times and the newest edition was released on September $15,2016 .{ }^{11}$

A big update was also seen with the FOIA Improvement Act of 2016. In line with the prior initiatives, the public should be able to inspect in electronic format each agency's opinions, policy, interpretations, and copies of all records that have been released. Agencies also have the ability to withhold information only if disclosure is prohibited or could cause harm to a protected interest and should determine if partial disclosure is possible. ${ }^{12}$ Agencies must also submit to the Attorney General and Director of the Office of Government Information Services the number of times they deny a records request and how many records they have made available in electronic format.

\section{Initiative Success}

To decide if the initiatives set forth have been successful one can take a look at whether or not the prior mentioned goals were accomplished. President Obama wanted to make the federal government even more accessible to the public than the prior administrations by developing consistent policies and promoting the same culture of openness. Different agencies were forced to work together from the start to create the Open Government Directive that made it easy to have standards to use when creating policy framework for each department. The Office of Information Policy has been able to work from the initiatives set forth by the former president and that has influenced the creation of a DOJ Open Government Plan that would not have existed otherwise. OIP creates guides to help agencies become more FOIA compliant, they work on standardizing 


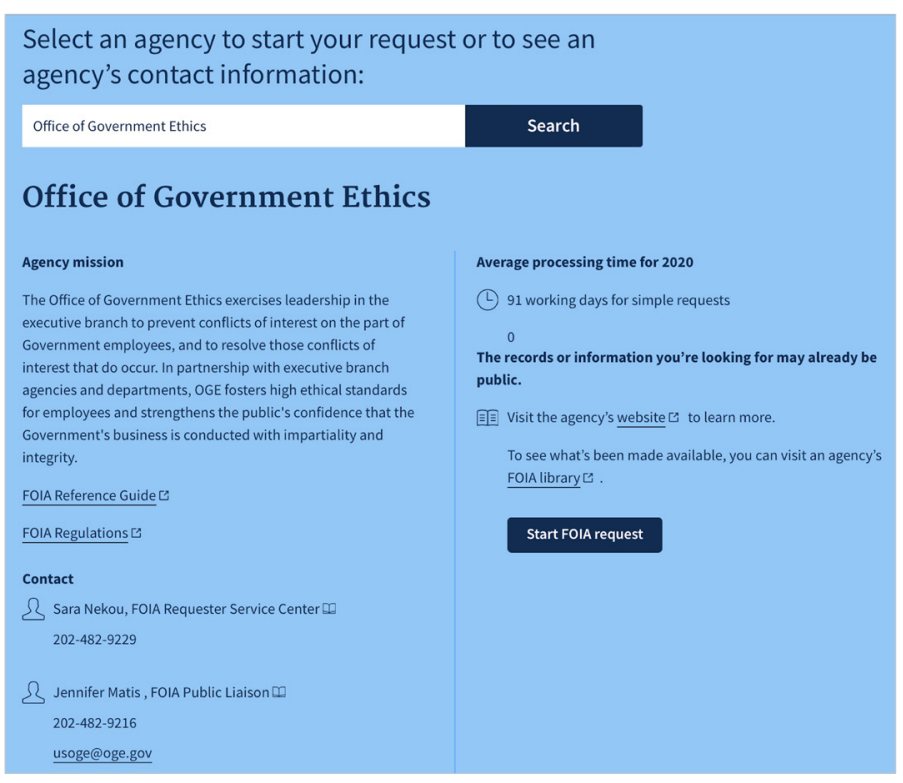

Figure 1. Screen capture of starting an FOIA request for the Office of Government Ethics on FOIA.gov. https://www.foia.gov/?id=5e5084cd5047-4fd9-8d19-4af473b24796\&type=component.

FOIA regulation through the use of a template agencies use to develop their own FOIA regulations. ${ }^{13}$ They continue to be the vehicle for the DOJ and issue guidance for the reports submitted by an agency's Chief FOIA Officers for assessment of their progress in order to identify areas to improve to increase efficiency as well as decrease backlog.

In 2011, the DOJ with the OIP launched FOIA.gov which provides individuals with information on how to submit a FOIA request and the ability to start a FOIA request directly on the site. They have so far been able to partially deliver on that promise and have some offices such as the Office of Government Ethics which is pictured in Figure 1 that allow that to be an option.

The page even details the average processing time from 2020 which shows as ninety-one working days for this chosen office. Numbers and names for FOIA contacts in that office are also provided.

The OIP also provides a clear assessment of how well agencies are keeping up with FOIA requests and discusses this in their Summary of Agency Chief FOIA Officer Reports. Looking at the most recent one published in 2020, 36 medium and highvolume agencies reduced their backlog or there was none to reduce. Shown in Figure 2, it was found that 26 agencies were actually increasing in a backlog of more than five requests, and seven were finding themselves with a slight increase (parameter of five) or a constant backlog. ${ }^{14}$ However, findings show that the number of requests is increasing in 10 of the agencies found to be backlogged. Agencies are reducing their backlog, so it is showing proof that government transparency is increasing.

\section{COMPARISON OF BACKLOG FY18 - FY19}

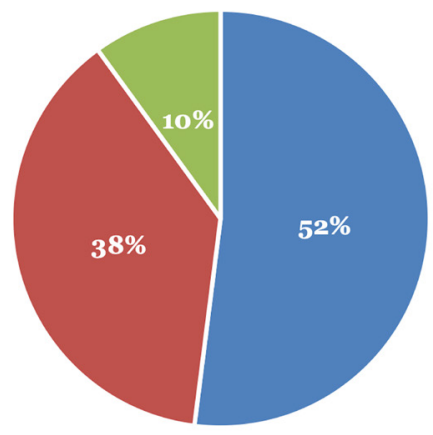

- 36 Agencies Reduced their Backlog or Had No Backlog to Reduce

- 26 Agencies Had a Backlog Increase Greater than 5

- 7 Agencies Had a Slight Increase (within 5) or Constant Backlog

Figure 2. Pie chart comparing agency increase or reduction in FOIA requests backlog in the financial year 2018-2019. https://www.justice.gov/ oip/page/file/1319661/download.

The OIP has done an excellent job of stating in their summary that agencies who are spending more than 20 days with simple requests need to review their current FOIA processes and finish up the oldest requests. With ten agencies still backlogged, the OIP will need to continue to guide and support these agencies to identify inefficiencies to reduce their respective backlog and increase FOIA compliance.

\section{Dissemination of Information/Access Issues}

Finding information detailing the Office of Information Policy's history and present-day functions is not overly complex. The Office of Information Policy has a very extensive website that is easily accessible through public channels such as the search engine Google. There may be some difficulty if an individual is not aware that the office falls underneath the Department of Justice's website and jurisdiction. However, once they navigate to the main section of the Office of Information Policy's website the most important information is streamlined. Historical information on the FOIA is plainly presented as well as the more up to date changes that were implemented by President Obama. The main mission of OIP's efforts, which is to help with government transparency, is highlighted and the DOJ's Open Government Plans from the past to most current is clearly linked. A user does not have to navigate any of the more complex databases such as govinfo.gov that may return too little or too many results based on parameters set by the user. Summary reports of each agency's success with FOIA requests and backlog can also be located on the OIP website. 
All executive orders and memorandums are also available on the obamawhitehouse.archives.gov websites that have been archived but warn they may link to broken pages. ${ }^{15}$ Only one document was not found through the titled archived pages, and it is the M-10-06 Memorandum to Agency and Department Executive Heads by Peter R. Orszag that referenced the open government directive set forth by President Obama. That memorandum is hosted on the whitehouse.gov website but is difficult to locate through the page's search function. This shows that there is an overall ease of finding presidential memorandums and executive orders, but the other communication between departments remains harder to find.

\section{Conclusion}

Attempts for greater government transparency have been increasing substantially within the last decade after more than 50 years of the Freedom of Information Act's passage. The FOIA passed in the 1960s has presented a lot of government information to the public throughout the years, even with the ability for agencies to claim exemptions from doing so. President Obama ushered in a new lease on improving government transparency with multiple executive orders and memorandums that helped to detail the transition. The Office of Information Policy has done an exceptional job in keeping up with cataloging all of this information for the general public in an easy to navigate website through the Department of Justice page and the FOIA. gov website. While information on the Office of Information Policy's guidelines and reviews was particularly easy to find, the search showed that finding communications between the OIP and each agency's FOIA office can be difficult to locate. Documents from the executive branch or OIP are easier to find than the work that is done before an agency presents their final FOIA regulation. Since the public may have an interest in these documents, it is important that communications and policy development of each executive agency are easier to find. Overall, the OIP does an excellent job of allowing their information to be incredibly easy to access and provide an exceptional model of the government transparency they wish to promote government wide.

Chelsea Webb (chels.webb94@gmail.com) is a student at Drexel University's School of Library and Information Science. This paper was written for INFO 680 US Government Information, Spring 2021, Professors Andrea Morrison and Jennifer Morgan.

\section{Notes}

1. History.com Editors, "Freedom of Information Act," accessed March 10, 2021, https://www.history.com/topics /1960s/freedom-of-information-act.

2. Freedom of Information Act, "What is FOIA?," accessed October 27, 2021, https:/www.foia.gov/about.html.

3. Freedom of Information Act, "Frequently Asked Questions, accessed October 27, 2021, https://www.foia.gov/faq.html.

4. US Department of Justice, "Organization, Mission and Functions Manual: Office of Information Policy," updated October 27, 2021, https://www.justice.gov/jmd/ organization-mission-and-functions-manual-office-information-policy.

5. US Department of Justice, "Organization, Mission and Functions Manual."

6. US Department of Justice, "Organization, Mission and Functions Manual."

7. Memorandum on Transparency and Open Government, 74 Fed. Reg. 4685 (Jan. 26, 2019).

8. Peter R. Orszag, "Memorandum for the Heads of Executive Departments and Agencies," Office of Management and Budget, December 8, 2009, https://www .whitehouse.gov/sites/whitehouse.gov/files/omb/memo randa/2010/m10-06.pdf.

9. Memorandum on Managing Government Records, 76 Fed. Reg. 75423 (Dec. 1, 2011).

10. Exec. Order No. 13,642, 3 C.F.R. 28111 (2013).

11. US Department of Justice, "Government Transparency," updated February 15, 2017, https://www.justice.gov/oip /government-transparency.

12. US Department of Justice, "The Freedom of Information Act, 5 U.S.C. $\$$ 552,” updated July 19, 2019, https:// www.justice.gov/oip/freedom-information-act-5-usc-552.

13. US Department of Justice, "Template for Agency FOIA Regulations," updated February 22, 2017, https://www. justice.gov/oip/template-agency-foia-regulations.

14. US Department of Justice, "Summary of Agency Chief FOIA Officer Reports for 2020 And Assessment of Agency Progress in FOIA Administration with OIP Guidance for Further Improvement," 13, https://www.justice.gov/ oip/page/file/1332196/download.

15. The White House, President Barack Obama, "Presidential Actions," accessed October 27, 2021, https://obamawhite house.archives.gov/briefing-room/presidential-actions. 